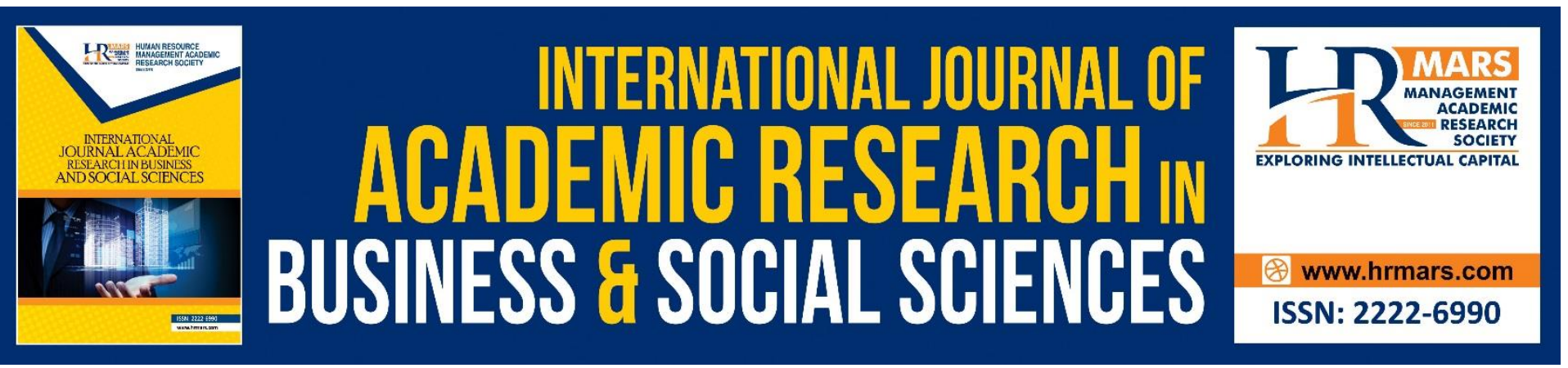

\title{
Enhancing Anaerobic Performance using Mindfulness Acceptance Commitment-Physical (MAC-P) Training Approach
}

Nur Haziyanti Mohamad Khalid, Nelfianty Mohd Rasyid, Norsilawati Abd Razak \& Thariq Khan Azizuddin Khan

To Link this Article: http://dx.doi.org/10.6007/IJARBSS/v8-i12/5319 DOI: $10.6007 /$ IJARBSS/v8-i12/5319

Received: 19 Nov 2018, Revised: 24 Dec 2018, Accepted: 02 Jan 2019

Published Online: 04 Jan 2019

In-Text Citation: (Khalid, Rasyid, Razak, \& Khan, 2018)

To Cite this Article: Khalid, N. H. M., Rasyid, N. M., Razak, N. A., \& Khan, T. K. A. (2018). Enhancing Anaerobic Performance using Mindfulness Acceptance Commitment-Physical (MAC-P) Training Approach. International Journal of Academic Research in Business and Social Sciences, 8(12), 1731-1741.

Copyright: (C) 2018 The Author(s)

Published by Human Resource Management Academic Research Society (www.hrmars.com)

This article is published under the Creative Commons Attribution (CC BY 4.0) license. Anyone may reproduce, distribute, translate and create derivative works of this article (for both commercial and non-commercial purposes), subject to full attribution to the original publication and authors. The full terms of this license may be seen at: http://creativecommons.org/licences/by/4.0/legalcode

Vol. 8, No. 12, 2018, Pg. 1731 - 1741

Full Terms \& Conditions of access and use can be found at http://hrmars.com/index.php/pages/detail/publication-ethics 


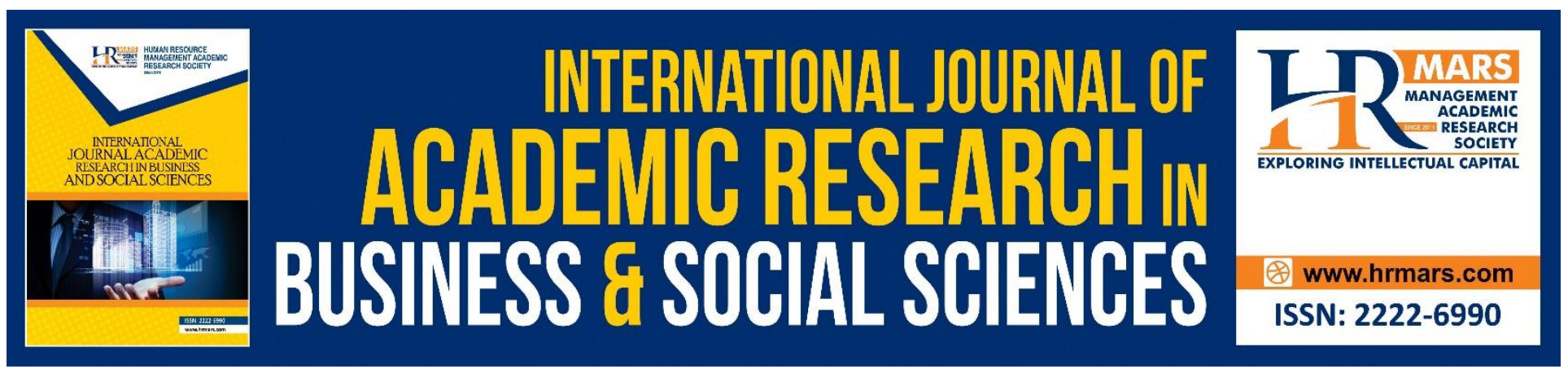

\title{
Enhancing Anaerobic Performance using Mindfulness Acceptance Commitment-Physical (MAC-P) Training Approach
}

\author{
Nur Haziyanti Mohamad Khalid", Nelfianty Mohd Rasyid, Norsilawati \\ Abd Razak, \& Thariq Khan Azizuddin Khan \\ Faculty of Sports Sciences and Coaching, Sultan Idris Education University, Tanjung Malim, \\ Perak, Malaysia \\ Email: nur.haziyanti@fsskj.upsi.edu.my
}

\begin{abstract}
This study examined the effect of Mindfulness Acceptance Commitment-Physical (MAC-P) on anaerobic performance. The MAC-P specifically designed for anaerobic training, and has its validity and reliability. The study used non-randomized control group pretest-posttest design. Research instrument consisted of Wingate Test to evaluate anaerobic performance in terms of peak power, mean power and anaerobic fatigue index. Subjects were semester one Coaching Science students from Sultan Idris Education University, divided into MAC-P $(n=21)$, PST $(n=21)$ and control $(n=21)$ group. Analysis of Covariance (ANCOVA) showed significant effect of the intervention on the achievement of post anaerobic peak power $[F(2,59)=19.18, p<0.05]$ and mean power $[F(2,59)=$ $3.60, p<0.05]$. However, the interventions did not have significant effect on post anaerobic fatigue. In conclusion, the MAC-P has prominent effect on anaerobic performance and attempts to be an alternative towards improving anaerobic performance. This finding can be used as a reference for coaches to improve anaerobic performance among athlete.

Keywords: Mindfulness Acceptance Commitment - Physical (MAC-P), Psychological Skill Training (PST), Wingate Test, Anaerobic Peak Power, Anaerobic Mean Power, Fatigue Index
\end{abstract}

\section{INTRODUCTION}

Anaerobic parameters play a major role in physical activity which requiring the use of ATP-CP energy or lactate energy systems. Anaerobic fitness components such as power and speed are indispensable in anaerobic activity such as sprinting, jumping, and kicking. Among the factors that determine the anaerobic fitness are the capacity and anaerobic fatigue indexes (McArdle, Katch, \& Katch, 2015). The 30-second Wingate test can be used to examine the endurance and anaerobic power in an all-out maximum effort that lasts 30 seconds with a resistive load added equal to $5 \%$ of participant's body weight. It determine an anaerobic capacity level based on peak power, mean power, relative power, 
total work and fatigue index (McArdle et al., 2015). In such activity, the 30-second period is the optimum period for testing the overall anaerobic or anaerobic power average. The first five seconds of interval is the ability of the athlete to generate power immediately using the power system. For the remaining period, the athlete's ability to pursue power generation using short-term energy systems (Lovell, Kerr, Wiegand et al., 2013). The whole test requires energy generated from the phospagen system and lactic acid (McArdle et al., 2015). Therefore, subjects undergoing the Wingate test will receive 60 or 66 percent to 85 percent ATP energy from phospagen components and glycolytic components (McArdle et al., 2015; Baechle \& Earle, 2008).

In order to achieve optimum anaerobic training performance, mental behavior also plays an important role other than physical skills and techniques. Since, physical activity is implemented in many ways and context, and is influenced by psychological processes such as motivation and decision-making, psychological skills are required to meet the needs of physical activity (Biddle, Mutrie, \& Gorley, 2015). Many factors affecting the athlete's performance on sports involvement and physical training include the ability of the athlete's physical and sensory skills; environmental stimulus requirements such as competitive challenges; interpersonal problems, organizations and current issues experienced by individuals; natural psychological features such as action, cognitive-effective schemes affecting perception, interpretation and psychological responses to stimuli; and selfregulatory behavior such as cognitive, affective, physiological and motivational processes (Gardner \& Moore, 2006). Therefore, some psychological skills that can help regulate athlete's behavior to address specific challenges. Among these skills are focus and attention, motivation, hardiness, arousal regulation, function of cognitive perception, multiple self-construct, personal and life development skills, coping skill, communication, leadership and recovery skills (Birrer \& Morgan, 2010).

Mindfulness Acceptance Commitment (MAC) is one of the alternative strategies towards improving the athlete's performance (Gardner \& Moore, 2006). This approach differs from conventional Psychological Skill Training (PST) approaches as it does not operate on the notion that negative internal factors need to be altered, controlled or discarded. The MAC model suggests that athletes do not need to control, alter or remove negative internal emotions to ensure optimum performance results. Through mindfulness and acceptance skills, athletes can increase focus on tasks, and thus improve performance. Unlike the PST approach that focuses on reducing negative thinking through imagery, visualization, relaxation or focus attention, the MAC approach is directly towards improving sports performance without focusing on the negative emotions (Gardner \& Moore, 2006). Some studies have shown that the MAC strategy is able to improve sports performance. For example, teenage athletes showed improvement in mindfulness performance, focus, acceptance, flow and performance in springboard events (Schwanhausser, 2009). Swimming athletes trained with MAC skills are much focused on body sensation and accept whatever emotions and negative thoughts they experience (Bernier, Thienot, Codron, \& Fournier, 2009). While MAC groups get a higher performance rating from their coach as compared to PST group (Lutkenhouse, Gardner, \& Moore, 2010). 
In this regard, MAC approach to sports provides a new dimension of psychological skills training methods. Athletes no longer control, alter or eliminate the symptoms of competitive anxiety in order to improve optimum performance. Through mindfulness techniques and acceptance-based strategies, athletes can focus on physical tasks that have a better impact on their performance (Gardner \& Moore, 2006). The MAC is an exercise that has seven training components: 1) providing subjects with psycho-education; 2) introduction of mindfulness and cognitive defusion; 3) introduction of values and value driven behaviors; 4) introduction of acceptance concept; 5) the ability to increase commitment; 6) integration of mindfulness, acceptance, and commitment skills; and 7) skills to maintain and improve mindfulness, acceptance, and commitment. In another study, MAC has been modified due to population factors, such as MAC-A (Schwanhausser, 2009). However, training modifications do not alter the skill development phase in the MAC, but rather emphasize MAC delivery patterns that are more easily understood and tailored to the purpose of training.

Based on the development of the Mindfulness Acceptance Commitment model, MAC has been modified to the Mindfulness Acceptance Commitment-Physical (MAC-P) with the addition of Physical $(P)$ elements. MAC-P is used to improve physical training performance as in anaerobic exercises. MAC-P training is a modular form. The objective of the whole MAC-P training module is to provide knowledge and skills on MAC-P training; ensuring the subject applied MAC-P skills to improve the performance in anaerobic training; and ensure the subject is comfortable and confident to produce better performance in anaerobic training. The contents of the MAC-P module (Figure 1) still comprise the main components of the MAC module (Gardner \& Moore, 2006), but are integrated with training towards improving physical performance in anaerobic activity. Therefore, a study has been conducted to test the effectiveness of MAC-P on anaerobic performance, particularly in the Wingate test. 
INTERNATIONAL JOURNAL OF ACADEMIC RESEARCH IN BUSINESS AND SOCIAL SCIENCES Vol. 8, No. 12, Dec, 2018, E-ISSN: 2222-6990 @ 2018 HRMARS

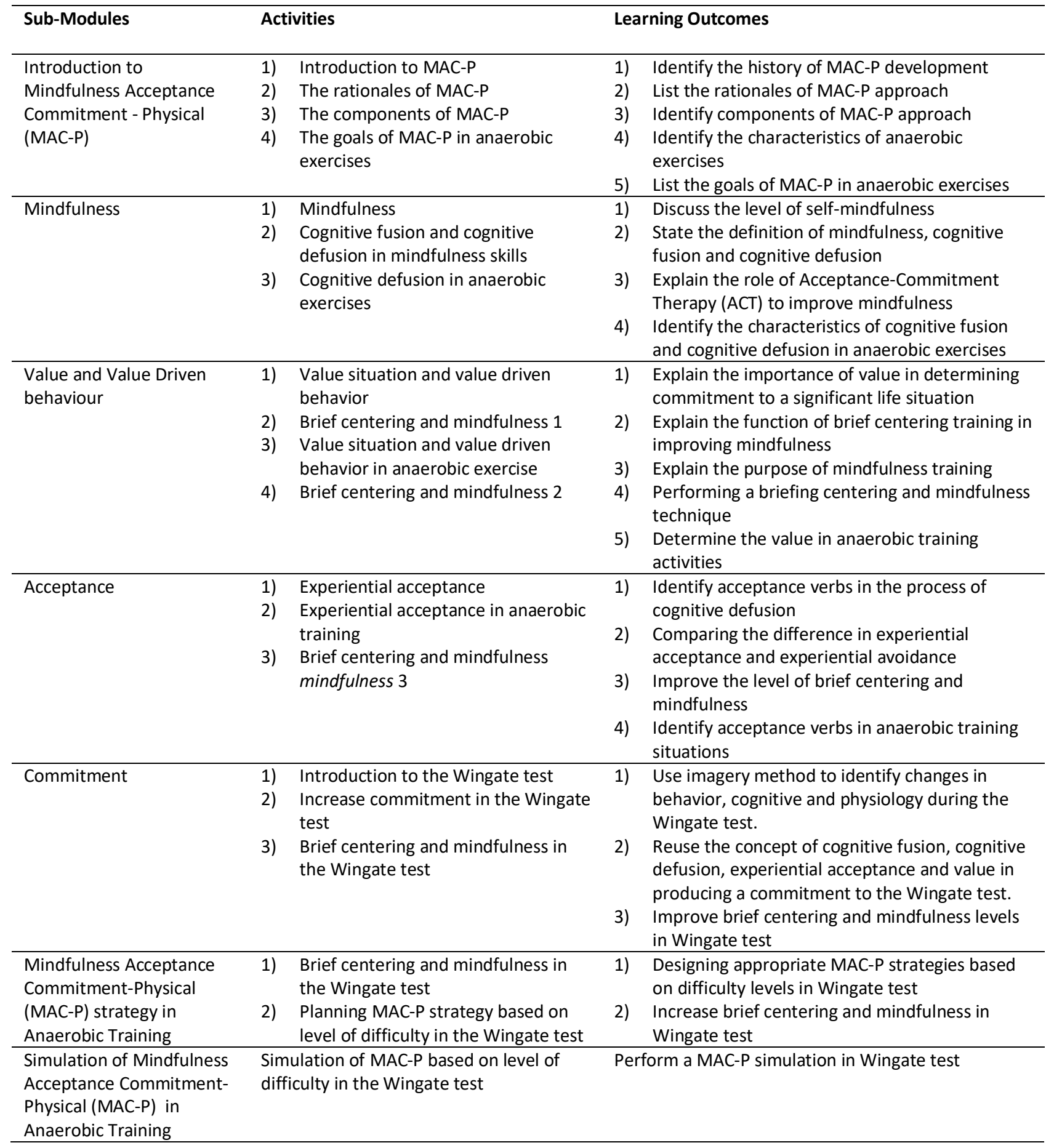

Fig.1. Summary of MAC-P module content and learning outcomes 


\section{METHODOLOGY}

The study was used non-randomized control group pretest-posttest design (Ary, Jacobs, \& Razavieh, 2010). Purposive sampling method was used to select 62 semester one undergraduate students of Coaching Sciences from Sultan Idris Education University. In order to avoid bias selection, the subjects were standardized using ranking methods based on their pre test performance to be included into Mindfulness Acceptance Commitment-Physical (MAC-P) $(n=21)$, Psychological Skill Training $(n=21)$, and control $(n=21)$ group. The total number of subjects per group is sufficient based on Cohen Statistical Power of Analysis with a significant level of 0.05 (2-tailed), the effect of size is 0.40 (larger), and power is 0.80 (Cohen, 1992).

Subjects were required to undergo pre-anaerobic endurance testing using the 30 -second Wingate test. The test was used to measure anaerobic capacity, especially for the lower part of the body. Subjects need to pedal with Ergometer bicycles for 30 seconds. Anaerobic capacity was measured based on peak power, mean power and fatigue index. Anaerobic peak power refers to the highest level of power measured in any interval of five seconds during the Wingate test. Mean power is the average peak power obtained over 30 seconds when the Wingate test is carried out and measured using watts $(\mathrm{W})$. The fatigue index refers to the reduced power rate from the peak of power until the test ends.

Subjects were exposed to MAC-P and PST interventions for seven weeks. The PST group was trained to self-talk and pursed-lip breathing (PLB) techniques; whereas for the control group who did not receive any special treatment, the researcher informed that the control group collaboration was only needed during the post test implementation. The purpose of the control group was to be free from any form of intervention to provide an alternative explanation of the treatment effects. All subjects including the control group underwent post- anaerobic test which was the same test conducted during pre-test. The post test schedule begins once MAC-P and PST intervention session ends. Researchers need to expedite the post-test process to avoid threats to internal validity of the experiment (Ary et al., 2010).

\section{RESULTS}

\section{MAC-P effect on Anaerobic Peak Power}

ANCOVA (see Table 1) shows that there is a significant intervention effect on post-anaerobic peak power, when $F(2,59)=19.18, p<0.05$, eta squared $=0.39$ (moderate). The result shows that by controlling the pre-anaerobic peak power test score, interventions significantly affect the post anaerobic peak power. The pairwise comparison tests showed significant differences between MAC$P$ and PST groups $(p<0.05)$, MAC-P and control $(p<0.05)$ and PST and control $(p<0.05)$. The highest available post-anaerobic peak power score is MAC-P $(M=769.53)$, compared to PST $(M=669.04)$ and control $(M=547.79)$. 
INTERNATIONAL JOURNAL OF ACADEMIC RESEARCH IN BUSINESS AND SOCIAL SCIENCES

Vol. 8, No. 12, Dec, 2018, E-ISSN: 2222-6990 @ 2018 HRMARS

Table 1. Tests of Between-Subjects Effects on Anaerobic Peak Power

\begin{tabular}{ccccccc}
\hline Source & Sum of Squares & df & $\begin{array}{c}\text { Variance } \\
\text { Estimate } \\
\text { (Mean } \\
\text { Square) }\end{array}$ & F & Sig & d \\
\hline $\begin{array}{c}\text { Pre-anaerobic peak } \\
\text { power }\end{array}$ & 802530.34 & 1 & 802530.34 & 60.31 & .00 & .51 \\
$\begin{array}{c}\text { Intervention group } \\
\text { Error }\end{array}$ & 510505.04 & 2 & 255252.52 & 19.18 & .00 & .39 \\
Total & 785110.96 & 59 & 13306.97 & & & \\
\hline
\end{tabular}

\section{MAC-P effect on Anaerobic Mean Power}

One Way Analysis of Covariance (see Table 2) shows that there is a significant intervention effect on post-anaerobic mean power, when $(2,59)=3.60, p<0.05$, eta squared $=0.11$ (small). The result shows that by controlling the pre-anaerobic mean power test score, interventions significantly affect the post anaerobic mean power. The pairwise comparison tests showed no significant differences between MAC-P and PST groups ( $p>0.05)$, and PST and control group ( $p>0.05)$. However, there was a significant difference between the MAC-P group and the control ( $p>0.05)$. The highest available post anaerobic mean power test score is for MAC-P group ( $M=466.22)$, compared to PST group (M $=448.72)$ and control group $(M=425.28)$.

Table 2. Tests of Between-Subjects Effects on Anaerobic Mean Power

\begin{tabular}{ccccccc}
\hline Source & $\begin{array}{c}\text { Sum of } \\
\text { Squares }\end{array}$ & df & $\begin{array}{c}\text { Variance Estimate } \\
\text { (Mean Square) }\end{array}$ & F & Sig & d \\
\hline $\begin{array}{c}\text { Pre-anaerobic mean } \\
\text { power }\end{array}$ & 213863.56 & 1 & 213863.56 & 86.84 & .00 & .60 \\
$\begin{array}{c}\text { Intervention group } \\
\text { Error }\end{array}$ & 17725.18 & 2 & 8862.59 & 3.60 & .03 & .11 \\
Total & 145307.94 & 59 & 2462.85 & & & \\
\hline
\end{tabular}

\section{MAC-P effect on Anaerobic Fatigue}

ANCOVA (see Table 3 ) shows that there is no significant intervention effect on post-anaerobic fatigue scores when $F(2,59)=0.21, p>0.05$, eta squared $=0.01$ (small). These results show that by controlling pre-anaerobic fatigue score, interventions do not significantly affect post-anaerobic fatigue tests score. The post-anaerobic fatigue score for MAC-P group $(M=63.92)$, PST group $(M=67.56)$ and control $(\mathrm{M}=66.85)$ are almost same. 
INTERNATIONAL JOURNAL OF ACADEMIC RESEARCH IN BUSINESS AND SOCIAL SCIENCES

Vol. 8, No. 12, Dec, 2018, E-ISSN: $2222-6990$ @ 2018 HRMARS

Table 3. Tests of Between-Subjects Effects on Anaerobic Fatigue

\begin{tabular}{ccccccc}
\hline Source & Sum of Squares & df & $\begin{array}{c}\text { Variance Estimate } \\
\text { (Mean Square) }\end{array}$ & $\mathbf{F}$ & Sig & d \\
\hline Pre-anaerobic fatigue & 398.79 & 1 & 398.79 & 1.20 & .28 & .02 \\
Intervention group & 142.12 & 2 & 71.07 & .21 & .81 & .00 \\
Error & 19664.15 & 59 & 333.29 & & & \\
Total & 295421.82 & 63 & & & \\
\hline
\end{tabular}

\section{DISCUSSION}

The result showed that there was a major intervention effect on post anaerobic peak power and mean power after controlling covariate variables in the population. The MAC-P group showed the highest achievement in post-anaerobic peak power and anaerobic mean power compared to PST and control groups. Based on this finding, researchers found that MAC-P intervention contributed to the tendency of the subject to produce a good score in anaerobic peak power and mean power in the Wingate test. Anaerobic exercises in Wingate tests are intermittent exercises and shorter periods (Kenney, Humphrey, Bryant, \& Mahler, 1995). However, motivational factors can affect Wingate test achievement and increase peak power scores (Bar-Or, 1987). In this regard, psychological skills training play a role in the implementation of anaerobic training in the Wingate test.

Based on the results, MAC-P module is capable of applying athletes with mindfulness elements such as acceptance, non-judgmental, openness, self-respect, and non-reactive. Mindfulness training improves experiential acceptance (Hayes, Strosahl, \& Wilson, 1999). As a result, athletes receive perceptions about the status of anaerobic performance without thinking to control or forget about it. Mindfulness also makes individuals clear of values during Wingate tests (Shapiro, Carlson, Astin, \& Freedman, 2006). With value clarity, athletes can identify conflicts between personal values, and task goals, thereby enhancing self-sufficiency and self-determination (Koestner, Lekes, Powers, \& Chicoine 2002). Eventually Mindfulness also improves motivational, personal, and self-developed skills during the Wingate test. MAC-P can also improve self regulation (Shapiro et al., 2006; Koestner et al., 2002; \& Coffey, Hartman, \& Fredrickson, 2010). Athletes who conduct self-regulation during Wingate tests can handle negative emotions such as fatigue, anger, and anxiety, as well as improving other skills such as arousal controls, coping, and communication. Thus MAC-P improves psychological flexibility so that athletes can adapt to cognitive, emotional and behavioral changes in response to environmental stimuli during Wingate test (Carmody, Olendzki, Baer, \& Lykins, 2009).

This study also found that intervention did not have a significant effect on the reduction of anaerobic fatigue in the Wingate test. PST group showed higher anaerobic fatigue score followed by MAC-P and control group. This situation explained that PST groups are less resistant than MAC-P and controls groups. Based on anaerobic fatigue norms, post-anaerobic fatigue scores for all groups are at a weak level (Coppin, Edward, Bressel, \& Wagner, 2012). Based on this result, it can be seen that fatigue rate, or anaerobic fatigue, is a reduction in percentage of power generation during testing and it 
represents the amount of ability to produce ATP through ATP-PC and glycolytic energy systems (Marino,Gard, \& Drinkwater, 2011; \& Gandevia, 2001). Thus, higher fatigue rates indicate that subjects cannot maintain longer workloads and unable to maintain a better anaerobic endurance (Dotan, 2006). According to verbal reflection by the subjects after finishing the post-Wingate test, researcher found that most of the subjects were excessively focused to produce peak power score, thus unable to maintain anaerobic power to the end of time. Based on irony thinking theory, fatigue will make the subject tended to act and think in a way that is contrary to the proper emotion, behavior and cognition. Therefore, not only the body, but also the subject's mind is filled with tiredness and fatigue condition (Janelle, 1999). As such, unlike capability of maintaining peak power and mean power score, MAC-P or PST exercises in fact can not help the subject to deal with fatigue during the Wingate test.

Based on the findings of the study, the MAC-P training module is more able to improve the performance of anaerobic power and mean power in the Wingate test. According to Gardner and Moore (2006), although the PST method is a conventional method that has always been used in sports, but with MAC-P, the psychological skills training method now has an alternative, with the belief that sports performance can be improved without prior focus on the process of controlling, altering or adjusting psychological skills. Hence, both MAC-P and PST modules can be adopted and improved to produce better physical performance findings in the future.

\section{ACKNOWLEDGEMENT}

This article is based on the work of Doctor of Philosophy (Sports Psychology) by the first author, part of which is supported by the Sultan Idris Education University Grants (GPU Code: 2017-0121-106).

\section{REFFERENCES}

Ary, D., Jacobs, L. C., \& Razavieh, A. (2010). Introduction to research in education ( ${ }^{\text {th }}$ ed). Wadsworth: Cengage Learning.

Baechle, T. R. \& Earle, R. W. (2008). Essentials of Strength Training and Conditioning (3 ${ }^{\text {rd }}$ ed). China: Human Kinetics.

Bar-Or, O. (1987). The Wingate anaerobic test an update on methodology, reliability and validity. Sports Medicine, 4, 381-394.

Bernier, M., Thienot, E., Codron, R., \& Fournier, J. F. (2009). Mindfulness and acceptance approaches in sport performance. Journal of Clinical Sports Psychology, 4, 320-333.

Biddle, S. J. H., Mutrie, N., \& Gorley, T. (2015). Psychology of physical activity: determinants, wellbeing and interventions ( $3^{\text {rd }}$ ed). London: Routledge.

Birrer, D. \& Morgan, G. (2010). Psychological skills training as a way to enhance an athlete's performance in high-intensity sports. Scandinavian Journal of Medicine and Science in Sports, $20(2), 78-87$.

Carmody, J., Olendzki, N., Baer, R. A., \& Lykins, E. L. B. (2009). An empirical study of the mechanisms of mindfulness in a mindfulness-based stress reduction program. Journal of Clinical Psychology, 65, 613-626. 
INTERNATIONAL JOURNAL OF ACADEMIC RESEARCH IN BUSINESS AND SOCIAL SCIENCES

Vol. 8, No. 12, Dec, 2018, E-ISSN: 2222-6990 @ 2018 HRMARS

Coffey, K. A., Hartman, M., \& Fredrickson, B. L. (2010). Deconstructing mindfulness and constructing mental health: Understanding mindfulness and its mechanisms of action. Mindfulness, 1, 235253.

Cohen, J. (1992). A Power Primer. Psychological Bulletin, 112(1), 155-159

Coppin, E., Edward, M. H, Bressel, E., \& Wagner, D. R. (2012). Wingate anaerobic test reference values for male power athletes. International Journal of Sports Physiology and Performance, 7, 232236.

Dotan, R. (2006). The Wingate anaerobic test's past and future and the compatibility of mechanically versus electro-magnetically braked cycle-ergometers. European Journal of Applied Physiology, 98(1):113-116.

Gandevia, S. C. (2001). Spinal and supra-spinal factors in human muscle fatigue. Physiological Reviews, 81(4), 1725-1789.

Gardner, F. L. \& Moore, Z. E. (2006). Clinical sport psychology. Champaign, IL: Human Kinetics.

Hayes, S. C, Strosahl, K. D., \& Wilson, K. G. (2012). Acceptance and commitment therapy: The process and practice of mindful change ( $2^{\text {nd }}$ ed.). New York, NY: The Guilford Press.

Janelle, C. (1999). Ironic Mental Processes in Sport: Implications for Sport Psychologists. Sport Psychologist 13(2), 201-220.

Kenney, W., Humphrey, R., Bryant, C. \& Mahler, D. (1995). ACSM's guidelines for exercise testing and prescription. Baltimore, Md.: Williams \& Wilkins.

Koestner, R., Lekes, N., Powers, T. A., \& Chicoine, E. (2002). Attaining personal goals; Selfconcordance plus implementation intentions equal success. Journal of Personality and Social Psychology, 83, 231-244.

Lovell, D., Kerr, A., Wiegand, A., Solomon, C., Harvey, L., \& McLellan, C. (2013). The contribution of energy systems during the upper body wingate anaerobic test. Applied Physiology, Nutrition and Metabolism, 38(2), 216-219.

Lutkenhouse, J. M., Gardner, F. L., \& Moore, C. E. (2010). A randomized controlled trial comparing the performance enhancement effects of Mindfulness-Acceptance-Commitment (MAC) performance enhancement and psychological skills training procedures. In R. W. Thompson, K. A. Kaufman, L. A. De Petrillo, C. R. Glass, \& D. B. Arnkoff (Eds.). One Year Follow-Up of Mindful Sport Performance Enhancement (MSPE) With Archers, Golfers, and Runners. Journal of Clinical Sport Psychology, 5, 99-116.

Marino, F. E, Gard, M., \& Drinkwater, E. (2011). The limits to exercise performance and the future of fatigue research. British Journal of Sports Medicine, 45, 65-67.

McArdle, W. D., Katch, F. I., \& Katch, V. L. (2001). Exercise physiology. Energy, nutrition, and human performance. Lippincott Williams \& Wilkins, Baltimore, USA. 
INTERNATIONAL JOURNAL OF ACADEMIC RESEARCH IN BUSINESS AND SOCIAL SCIENCES

Vol. 8, No. 12, Dec, 2018, E-ISSN: 2222-6990 @ 2018 HRMARS

Schwanhausser, L. (2009). Application of the Mindfulness-Acceptance-Commitment (MAC) protocol with an adolescent springboard diver: The case of Steve. Journal of Clinical Sport Psychology, 3, 377-396.

Shapiro, S. L., Carlson, L. E., Astin, J. A., \& Freedman, B. (2006). Mechanisms of mindfulness. Journal of Clinical Psychology, 62, 373-386. 